\title{
Ascertaining the Influence of Politics on the Outcomes of the Implementation of the NHIS: Study of the Ga West District Mutual Health Insurance Scheme
}

\author{
Professor Feng Ying \\ Department of Management, Jiangsu University, Zhenjiang, PR China \\ Bright Dartey, \\ Department of Management, Jiangsu University, Zhenjiang, PR China \\ Emmanuel Gyabeng, \\ Department of Management, Jiangsu University, Zhenjiang, PR China
}

\begin{abstract}
The study was conducted to ascertain the influence of politics on the outcomes of the implementation of the NHIS: study of the Ga West District Mutual Health Insurance Scheme (DMHIS). The study used the quantitative research methods which involved the distribution of questionnaires and through the random sampling technique, to reach the respondents. Questionnaires were distributed to 200 respondents dwelling in the Ga West District of Accra, Ghana after which a simple statistical tool, specifically the linear regression was used to analyze the data collected. The study revealed that over-ambitiousness of the NHIS policy, political message, staff selection not based on merit, policy uncertainty are the main political tenets that hinder the implementation of the Ga West District Mutual Health Scheme.
\end{abstract}

Keywords: Public policy, policy implementation, national health insurance scheme, Ghana DOI: $10.7176 /$ PPAR/9-2-05

\section{Introduction}

Health care financing has been a growing concern to many developing countries in recent times (AddaeKorankye, 2013) and Ghana is not an exception. The organization Of Economic Co-operation and Development defines health insurance as 'a way to distribute the financial risk associated with the variation of individuals (pooling), (Agyeman, et al2013). Health insurance can also be defined as 'coverage that provides for the payment of benefits as a result of sickness or injury (Marcinko 2006). Ghana's various health policies formulated and implemented have been through: Free medical care, out of pocket payments, National Health Insurance Scheme and now the capitation grant (Amankwah \& Mireku, 2015). Prior to the country's independence, health delivery was explicitly by out of pocket payment. After the country gained independence from the British rule, it introduced free health care system. Unfortunately, this system could not be sustained due to economic challenges and scarcity of resources which eventually ushered in the 'cash and carry system'. Ghana therefore introduced the NHIS. By June 2009, coverage had gone up to $67.5 \%$ as compared to the $27 \%$ coverage in 2005(Durairaj, et al, 2010). The main objective in setting up the NHIS by the Government of Ghana is to assure equitable and universal access for all residents of Ghana to an acceptable quality package of essential healthcare. Rwanda provides health insurance to the poor in the informal sector through its community-based health insurance (CBHI), (Valéry et al, 2018). On the other hand, Uganda and Cameroon have community-based health insurance schemes that offer protection for the poor but are unsustainable because poor people can't contribute enough premiums to maintain the schemes (Aryeetey et al, 2012). Only Rwanda and Ghana have made significant progress toward providing universal coverage through a national health insurance scheme for the majority of their citizens (Habiyonizeye, 2013). It can clearly be seen that the NHIS enjoyed a well -crafted nature with a noble intention yet its implementation has suffered hiccups with its process marred with politics (Freeman F. K. Gobah, et al, 2011). The implementation stage has witness numerous political clashes over the allocation of resources. Undoubtedly, the stage has also experienced clientelism, cronyism, favoritism, nepotisms which suggest the politics of implementation especially in developing countries including Ghana. There have been a lot of studies on public policy implementation on Ghana's NHIS, but only few touches on the politics inherent in the policy implementation process and other restricting factors on the NHIS. Therefore, the aim of this study is to add to already existing literature by investigating this political play that affects the outcome of the implementation of the NHIS focusing on the Ga West Municipality and eventually giving some recommendations.

\section{Related Literature}

Implementation stage of the policy is an operational phase where policy is actually translated into action with the 
hope of solving some public problem. (Ayee,1994) in his study, 'An anatomy of public policy implementation: Case of Decentralization policies in Ghana explained how implementation of decentralization as reoccurred since first republic to the Provisional National Defense Council (PNDC). He brought to light some determinants of the outcomes of conflicts which he mentioned scarce resources, strategies and power positions the main determinants of who gets what, when and how. His findings suggested that there is a great conflict in implementation stage because large number of the state institutions has different interest as a result of multiplicity of veto points. To this extent, implementing decentralization in Ghana wouldn't be effective. On health, (Fusheini, 2016) on his 'Politico-Economic challenges of Ghana's National Health Insurance Scheme Implementation focuses on the economic and political implementation challenges based on empirical evidence from the perspectives of the different category of actors and institutions involved in the process. From his model, the study identifies political issues of over politicization and political interference from ruling party and time and timing of policy changes as main challenges. His study revealed some political play in selection of NHIS stuffs and also who gets what, when and how. (Koduah, et al, 2016) also argued that tension and complicated relationships between technical considerations and politics and bureaucratic versus public arenas of conflict are important influences that can cause items to fall and rise on policy agendas. Furthermore, the authors brought to light the confusion and uncertainties surrounding stakeholders' understanding of the NHIS policy issues. According to (Korankye, 2013), new and innovative ways are being developed by governments all over the world to ensure that basic health care is available to all at affordable prices and it's equitable. In the quest to sustain the NHIS by the government of Ghana, it introduced a levy for which all resources including fund to the district level are kept. This is consistent with the study of (Nsiah \& Aikens, 2013), where they noted that 'financially the scheme depended largely on subsidies and reinsurance from the National Health Insurance Authority for $89.8 \%$ of its revenue to the District Mutual Health Scheme showing centralized control of the scheme.

\section{Research model}

The research emphasizes the influences of politics on the outcome of the NHIS. Several studies have identified the existence of politics in the NHIS implementation. At home, (Kotoh, et al ,2017), based on an empirical model in their study on the factors that influence enrolment and retention in Ghana's National Health Insurance Scheme, noted that aside the core poor and poor households with many dependents, poverty was not the main reason for the low enrollment, instead, the negative influence of traditional risk-sharing arrangements, corruption, shortage of drugs and politics as the main bottlenecks to the enrollment of the NHIS. (Abiiro \& McIntyre, 2012), model on policy implementation also noticed the political challenges in the NHIS policy implementation and hence stated that these political challenges are controversial within Ghana and worldwide. (Imurana, et al, 2014) model on implementation challenges, revealed that poor leadership, corruption, lack of consensus, rapidity and politicization, lack of participation, poor sense of direction, limited understanding and management of the political challenges were the major implementation problems of the NHIS. Their findings revealed that the NHIS policy is so quick and overambitious just to maintain political office, a statement which is described by Grechyna, (2016) as rent seeking by politicians from the public.

The above literature reviews some discussions and findings on policy implementation, specifically, health policy implementation in Ghana. Although, the literature focuses on politicization of the National Health Insurance Scheme, it however, fails to mention these political tenets and their influence on the outcome of the NHIS. Therefore, this study aims to add to this already existing literature by studying these political tenets and the negative impact they have on the National Health Insurance scheme, a study on the Ga West Municipal Assembly.

Based on the above literature, the study adopted a model, figure 1, which reveals a relationship between the independent variables and the dependent variable. The researcher adopts this model since it gives a clear understanding of the relationship that exist between the independent variables and the failure of the National Health Insurance, specifically, Ga West Municipal Assembly. Together, the independent variables impact the total performance of the NHIS achievement. 


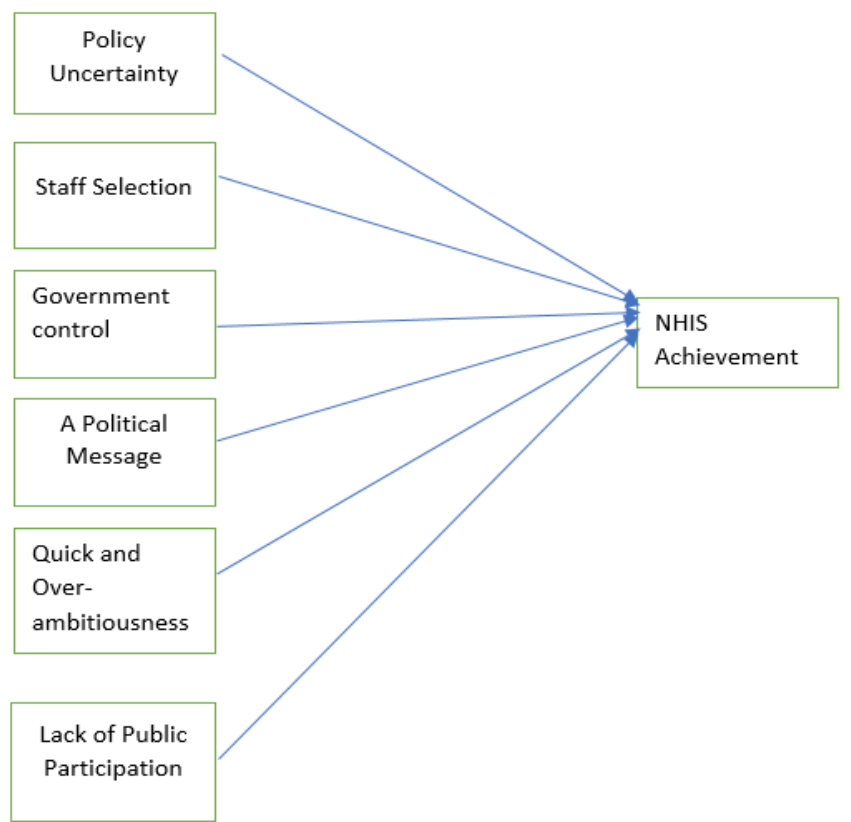

Figure 1. Research framework.

The above model hypothesizes that;

H1: There is a negative relationship between lack of public participation and the implementation of the NHIS (Ga West DMHIS)

$\mathrm{H} 2$ : There is a negative relationship between selection of NHIS staff and the implementation of the NHIS (Ga West DMHIS)

H3: There is a negative relationship between policy uncertainty and the implementation of the NHIS (Ga West DMHIS)

H4: There is a negative relationship between Quick and Over-ambitiousness and the implementation (Ga West DMHIS)

H5: There is a negative relationship between Government Control and the implementation of the NHIS (Ga West DMHIS)

H6: There is a negative relationship between Political Message and the implementation of the NHIS (Ga West DMHIS)

\section{Methodology}

The study used both primary and secondary data to ascertain the political tenets that thwart the implementation of Ghana's National Health Insurance Scheme at the Ga West Municipality. The study adopted the quantitative method that used a questionnaire to collect data from 200 respondents. These 200 respondents were selected using the simple random sampling technique. The questionnaires consisted of three parts: the first part was to survey the basic information of users including gender, age, education, marital status, occupation etc. The second part was to survey users' awareness of the NHIS policy and whether or not the premiums paid merit the treatment received. The third part was the main part of the questionnaire which was designed according to the political factors that hinder the smooth implementation of the NHIS using the Likert scale method. The 200 respondents selected through the random sampling technique were all dwellers in the Ga West Municipality. The municipality is one of the newly created municipalities and districts created in 2008. Its capital is Amasaman and occupies a land of approximately 305.4 qskm with about 193 communities. The data collected was analyzed using SPSS and hypothesis tested using a simple statistical tool, specifically the linear regression tool.

\section{Results \& Analysis}

This section presents analyses and discusses the results of the study. In an effort to come up with some inferential results, the study employed linear regression to ascertain the relationship that exist between the independent and dependent variables.

The table below reveals the outcome of the relationship between dependent variable and the independent variables of the study with the aim of testing the hypotheses of the study and is presented as follows; 
Table 1 Linear Regression result

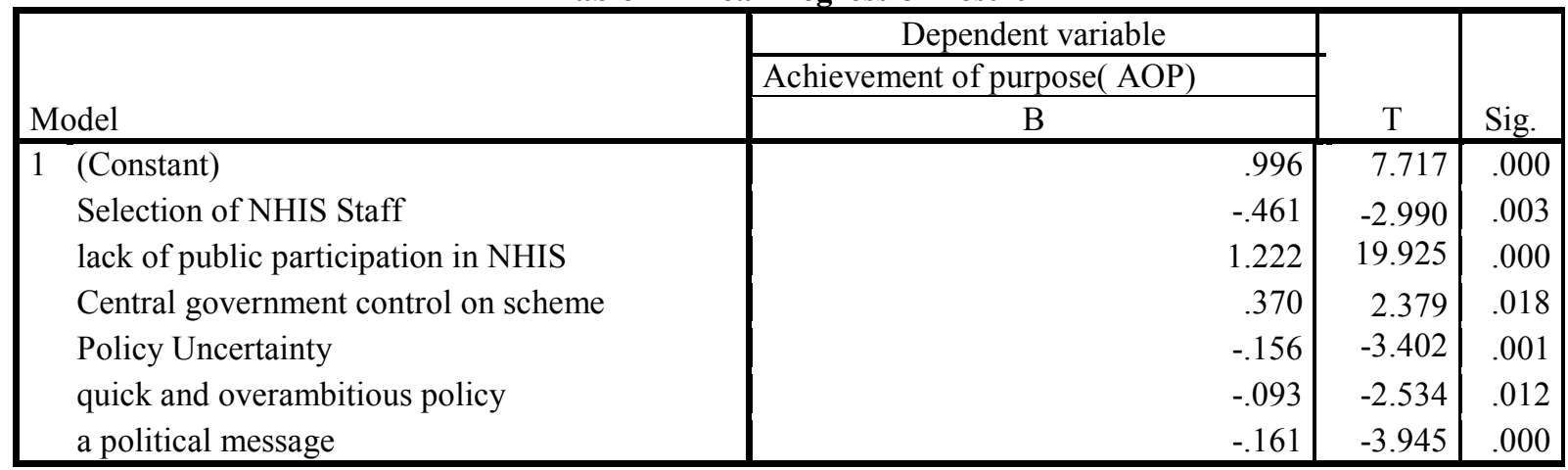

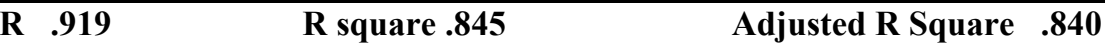

Having fixed our confidence interval level at $95 \%$, we considered models that can reasonably predict the relationship that exist between the independent variables and the dependent variable. According to the results in the table, most of the set of independent variables have negative influence on the dependent variable. As shown by the parameters in the table, the model fit very well and the results of the explanatory variables were relatively high and significant. The coefficient of determination R-square is 0.845 , it does explain the joint influence of the independent variables on the dependent variable. This implies that a unit change in all the independent variables could bring about $85 \%$ changes in the dependent variable (achievement of NHIS). The P value of (.000) is highly significant at 5\% level; this shows that the model is adequate. Furthermore, some of the variables had a negative relationship as hypothesized by the study, while others do not. The coefficient of quick and over ambitiousness of policy is (-.093) which implies that the more policy makers become overambitious and quick in taking policy decisions, the more it slows down the achievement of the NHIS and so also the lower the quick and over ambitiousness of policy making, the higher the chances of greater achievement of the NHIS. NHIS as a policy seen as a political message is also significant with $p$ value (.000) and negative coefficient (-.161) and the interpretation of this is that most of the decisions and utterances of the actors negatively influence the outcome of the NHIS implementation. Hence when there is an increase in political messages, there will be a decrease in NHIS achievement. Policy makers changing of policy direction has a significant and a negative relationship with the dependent variable. The negative relationship shows that inconsistencies in policy making affects the scheme the more, reducing its chances of achieving its main objective. The coefficient of selection of NHIS staff is negative (-.461) which implies that the higher selection of NHIS not based on merit, the higher the chances of the NHIS failing by $46 \%$. And so also, the higher selection is based on merit and competency, the lower the chances of the NHIS to fail. Lack of public participation had a positive relationship (1.222) with the dependent variable (achievement of the NHIS). The positive relationship reveals that the more the public is exempted from policy making, the higher the chances of the NHIS to materialize. In the same vein, the positive relationship between central government control and the achievement of the NHIS shows that it is not significant to the failure of the NHIS, hence the higher the chances of the NHIS to succeed under central government control.

Thus, based on these we accept the hypothesis which states that there is a negative relationship between Quick and Over ambitiousness of policy, Selection of NHIS Staff, A political Message and Policy uncertainty, to the achievement of the NHIS policy and then reject the other hypothesis which state that there is a negative significant relationship between, central government control and lack of public participation to the achievement of the NHIS policy.

\section{Discussion of Findings}

The cardinal objective of this work is to ascertain the influence of politics on the outcomes of the implementation of NHIS, using Ga West District Mutual scheme as a study. After analyzing the generated data on the cause of this work, the findings reveal that significant percentage of the respondents in the District agreed that there are some political tenets in the implementation of the NHIS, thus thwarting the desired outcome of the scheme. After testing the hypothesis, four of the hypotheses were accepted and two rejected. The R-Square stood at (.845) and a high significance value of (.000) with a 5 degree of freedom. The findings reveal that the NHIS policy is so quick and overambitious just to maintain political office, a statement which is described by (Grechyna, 2016) as rent seeking by politicians from the public. Ambitions compel one to free himself or herself from insecurity and vulnerability. Again, when competitors rise high, we are often consumed by jealousy. This eventually results in some quick and over-ambitiousness of decision making in order to maintain political offices. Due to how complex the making of policy is, any hasty decision can easily derail the desired outcome of it. It is therefore clear that most actors involved in the policy making of the NHIS in the Ga West municipality are consumed by the political ambitions which has affected the achievement of the NHIS. This is consistent with the 
study of (Imurana \& Haruna, 2014), which revealed the failure of NHIS due to over ambitiousness of the NHIS because of its comprehensive and universal nature in a growing and developing country like Ghana. The study also discovered that selection of NHIS staff was political and not based on merit and it's another bottleneck to the NHIS implementation. This is mostly termed as political nepotism. Selection of NHIS is seen as a vehicle for political rewards of party loyalties. Generally, this undermines the capacity and capability of scheme staffs in terms of skills, understanding of policy standards and goals and the ability to develop well planned programmes to tackle any unforeseen problem. This finding conforms to the findings of (Fushieni ,2016) whose study mentioned selection of staff members as a political tenet in the implementation of the NHIS.

The findings identified political messages as another threatening issue to the effectiveness of the NHIS and its sustainability. Social media tools allow politicians to directly speak to the public and in a way, spread their policies to them. There have been several questions about the activities of these politicians after been given these platforms. There is existence of harsh tone of political advertising, controversial techniques just to win power. Politicians seek votes at any cost, even including a degraded sense of public regard for the candidates and the electoral process. This gives rise to numerous speeches mudded in politics which reduces the number of utilizations of the scheme. In this case, an individual who has his loyalty to a different political party may find himself a stranger to the policies of the ruling government due to the politicization of speeches. This is consistent with the study of (Garrido \& Owusua, 2013) who identified speeches of politicization as a major challenge to the utilization of the NHIS.

Policy Uncertainty is an important factor in the model. There have been several health policy reversals in most African countries especially In Ghana and Nigeria. Nigeria for the past seven decades: during the colonial, military and civilian regimes, has witnessed several reversals with seven national short- to medium-term development plans from 1945 to date. There is a continuous fluctuation in budget allocation from $2.7 \%$ in 1985 to $26 \%$ in 2004 . These uncertainties affect program planning and implementation. National health policy should therefore be consistent irrespective of change (Emuakpor A, 2010). Our findings indicate the existence of inconsistencies in decision making by policy makers which eventually brings anxiety and frustration to the populace. The end result of this is a reduced number of utilizations. This is in conformity with the findings of (Anyika,2014) who revealed policy uncertainty as a challenge to implementing sustainable health insurance in Nigeria.

In contrast with the above accepted variable, the study revealed that lack of public participation has a positive relationship with the achievement of the NHIS. This is consistent with the works of (Gauvin et al, 2012) who argued that the existence of the public will rather ignite conflict and eventually reduce the pace of the NHIS implementation.

The study again revealed how essential central government control is in the quest to achieve the purpose of the NHIS. Undoubtedly, the NHIS framework ensures a decentralized system giving a level of autonomy to the district mutual health schemes. The DMHIS also mobilize resources at the local level to assist the work and efficiency of the NHIS. Unfortunately, most studies reveal the existence of fraud and corruption which compels the central government to monitor the activities at the local level. The central government determines the strategic direction of the health system at the District level. Central government's control, maximizes the opportunities in the environment, minimizes uncertainty factors and their impacts, and mobilizes human, financial and material resources to achieve unprecedented quality services. The government monitors and evaluates the work of all the NHIS staff at the local level. The government has developed institutions of clinical audit which has also helped to fight fraud and corruption. This finding however, is consistent with the study of (Fusheini et al, 2017). Their study revealed that central government control is a success driver to the NHIS implementation.

\section{Policy Implications}

Due to the context of this study and other related study, it is necessary to have a policy review in order to curb the existence of the political tenets worrying the NHIS implementation. In view of that, the study recommends the stakeholder's approach to solving this menace. Stakeholders are any party having an interest in the policy and in the case of the NHIS are the policy makers and the users. When the public feels part of the decisionmaking process, they become responsible to any outcome thereof. Hence no need to politically outsmart any member since there is a sense of collective responsibility. Each stakeholder therefore becomes a watchman on the other. Recruitments to scheme offices must be based on competencies and not political affiliations.

\section{Conclusion}

The study revealed that the NHIS' Implementation arena is littered with politics that hinders the outcome of the NHIS implementation. The study explored the Ga West District Mutual Health Scheme to demonstrate this implementation challenge on NHIS implementation and responses were gathered through the distribution of 200 questionnaires to 200 respondents all in the Ga West Municipality. The study reveals some political tenets in the 
implementation process and the degree to which they affect the general outcome of the NHIS. Through the use of linear regression, the study was able to ascertain the influence of politics on the outcome of the NHIS. Undoubtedly, the study has significant implication in some critical areas. The study helps us to revisit some of the biggest problems in the area of policy implementation. This helps policy makers to come out with necessary theories to tackle any problem confronted.

\section{Acknowledgments}

I say a very big thank you to my supervisor, Professor Feng Ying for her wonderful monitoring over my work. Again, I will like to thank all my research team members for their constructive criticisms and suggestions which have yielded a greater impact. Lastly, my acknowledgment goes to all the Darteys who in one way or the other contributed to the success of the work especially, Samuel Dartey, Joshua Dartey, Godson Mfarfo Dartey, Juliana Bender and Georgina Ampofuah.

\section{REFERENCES}

Abiiro, G. A., \& McIntyre, D. (2012). Universal financial protection through National Health Insurance: a stakeholder analysis of the proposed one-time premium payment policy in Ghana. Health policy and planning, 28(3), 263-278.

Addae-Korankye, A. (2013). Challenges of financing health care in Ghana: the case of national health insurance scheme (NHIS). International Journal of Asian Social Science, 3(2), 511-522.

Adei, D., Amankwah, E., \& Mireku, I. S. (2015). An Assessment of the National Health Insurance Scheme in the Sekyere South District, Ghana. Current Research Journal of Social Sciences, 7(3), 67-80.

Agyemang, K. K., Adu-Gyamfi, A. B., \& Afrakoma, M. (2013). Prospects and challenges of implementing a sustainable national health insurance scheme: the case of the Cape Coast metropolis, Ghana. Prospects, $3(12)$.

Aryeetey, G. C., Jehu - Appiah, C., Spaan, E., Agyepong, I., \& Baltussen, R. (2012). Costs, equity, efficiency and feasibility of identifying the poor in Ghana's National Health Insurance Scheme: empirical analysis of various strategies. Tropical Medicine \& International Health, 17(1), 43-51.

Ayee, J. R. (1994). An anatomy of public policy implementation: The case of decentralization policies in Ghana: Avebury.

Emmanuel, A. N. (2014). Challenges of implementing sustainable health care delivery in Nigeria under environmental uncertainty. Journal of Hospital Administration, 3(6), 113.

Fusheini, A. (2016). The politico-economic challenges of Ghana's national health insurance scheme implementation. International journal of health policy and management, 5(9), 543.

Fusheini, A., Marnoch, G., \& Gray, A. M. (2017). Implementation challenges of the National Health Insurance Scheme in selected districts in Ghana: evidence from the field. International Journal of Public Administration, 40(5), 416-426.

Gajate-Garrido, G., \& Owusua, R. (2013). The national health insurance scheme in Ghana: Implementation challenges and proposed solutions.

Gauvin, F.-P., \& Ross, M.-C. (2012). Citizen Participation in Health Impact Assessment: Overview of Issues: Report, May 2012: Centre de collaboration nationale sur les politiques publiques et la santé ....

Gobah, F. K., \& Zhang, L. (2011). The National Health Insurance Scheme in Ghana: prospects and challenges: a cross-sectional evidence. Global Journal of Health Science, 3(2), 90.

Grechyna, D. (2016). Political frictions and public policy outcomes. Journal of Comparative Economics, 44(3), 484-495.

Habiyonizeye, Y. (2013). Implementing community-based health insurance schemes: lessons from the case of Rwanda. Høgskolen i Oslo og Akershus. Fakultet for samfunnsfag.

Imurana, B., Kilu, R. H., \& Kofi, A.-B. (2014). The politics of public policy and problems of implementation in Africa: an appraisal of Ghana's National Health Insurance Scheme in Ga East District. International Journal of Humanities and Social Science, 4(4), 196-207.

Koduah, A., van Dijk, H., \& Agyepong, I. A. (2016). Technical analysis, contestation and politics in policy agenda setting and implementation: the rise and fall of primary care maternal services from Ghana's capitation policy. BMC health services research, 16(1), 323.

Kotoh, A. M., Aryeetey, G. C., \& Van der Geest, S. (2018). Factors that influence enrolment and retention in Ghana'National Health Insurance Scheme. International journal of health policy and management, 7(5), 443.

Marcinko, D. E., \& Hetico, H. R. (2007). Dictionary of health information technology and security: Springer Publishing Company.

Nsiah-Boateng, E., \& Aikins, M. (2013). Performance assessment of Ga district mutual health insurance scheme, greater Accra region, Ghana. Value in health regional issues, 2(2), 300-305. 
Ridde, V., Antwi, A. A., Boidin, B., Chemouni, B., Hane, F., \& Touré, L. (2018). Time to abandon amateurism and volunteerism: addressing tensions between the Alma-Ata principle of community participation and the effectiveness of community-based health insurance in Africa. BMJ global health, 3(Suppl 3), e001056.

Scott-Emuakpor, A. (2010). The evolution of health care systems in Nigeria: Which way forward in the twentyfirst century. Nigerian Medical Journal, 51(2), 53.

Soors, W., Devadasan, N., Durairaj, V., \& Criel, B. (2010). Community health insurance and universal coverage: multiple paths, many rivers to cross. 